\title{
CRISE GLOBAL DA ÁGUA: CONSTRUÇÃO DE CATEGORIAS ÉTICAS PARA ÁGUA A PARTIR DA VERIFICAÇÃO DAS PROBLEMÁTICAS GERADORAS DA CRISE
}

WATER GLOBAL CRISIS: CONSTRUCTION OF ETHICS CATHEGORIES TO WATER BY THE VERIFICATION OF THE CRISIS GENERATING PROBLEMS

Denise Schmitt Siqueira Garcia Doutora pela Universidade de Alicante na Espanha. Mestre em Direito Ambiental pela Universidade de Alicante - Espanha. Mestre em Ciência Jurídica. Especialista em Direito Processual Civil. Professora no Programa de Pós-Graduação Stricto Sensu em Ciência Jurídica, nos cursos de Doutorado e Mestrado em Ciência Jurídica, e na Graduação no Curso de Direito da Universidade do Vale do Itajaí - UNIVALI. Advogada. E-mail: denisegarcia@univali.br.

Paulo Márcio Cruz Pós-doutor em Direito do Estado pela Universidade de Alicante. Doutor em Direito do Estado pela Universidade de Santa Catarina (UFSC) e mestre em Instituições Jurídico Políticas pela mesma instituição. Coordenador e professor do Programa de PósGraduação Stricto sensu em Ciência Jurídica da Universidade do Vale do Itajaí SC. Professor visitante das Universidades de Alicante - ES, Perugia - Itália. E-mail: pcruz@univali.br.

Maria Claudia da Silva Antunes de Souza Doutora e Mestre em Derecho Ambiental y de la Sostenibilidad pela Universidade de Alicante - Espanha. Mestre em Ciência Jurídica pela Universidade do Vale do Itajaí UNIVALI. Professora Permanente no Programa de Pós-Graduação Stricto Sensu em Ciência Jurídica, nos cursos de Doutorado e Mestrado, e na Graduação no Curso de Direito, ambos da Universidade do Vale do Itajaí - UNIVALI. Coordenadora do Grupo de Pesquisa "Direito Ambiental, Transnacionalidade e Sustentabilidade" cadastrado no CNPq/EDATS/UNIVALI. Advogada. E-mail: mclaudia@univali.

\section{Resumo}

O presente trabalho terá como escopo trabalhar com a temática da crise global da água com a análise dos problemas encontrados e propostas de solução. Nesse diapasão elencou-se como objetivo geral analisar quais os problemas que agravam a crise global da água. Para tanto o artigo foi dividido em quatro partes: 1) A essencialidade da qualidade da água doce; 2) Direito ao acesso à água; 3) Falhas que geram a crise global da água e 4) Categorias éticas para água - uma proposta de solução. Extraindo-se, ao final, a consideração de que a água é um direito fundamental de primeira geração, eis que está ligada 
diretamente com o direito à vida; o mau uso da água fere diretamente as dimensões ambiental, social, econômica e tecnológica da sustentabilidade; há a necessidade de efetivação de uma governança não coercitiva, democrática e não corrupta; é preciso que haja participação e informação com instituições democráticas e a água deve ser considerada como água-vida, água-cidadania e água economia. Quanto à metodologia foi utilizado o método indutivo na fase de investigação; o cartesiano na fase de tratamento dos dados; e também o indutivo no relatório da pesquisa. Foram ainda acionadas as técnicas do referente, da categoria, dos conceitos operacionais, da pesquisa bibliográfica e do fichamento.

Palavras-chave: Água; Crise global; Direito à vida; Sustentabilidade.

\begin{abstract}
The present work has the scope to work with the theme of the global crisis with the analysis of the problems encountered and proposed solutions. In this context, the general objective is to analyze the problems that aggravate the global water crisis. Therefore, the article is divided into four parts: 1) The essentiality of freshwater quality; 2) Right to access to water; 3) Faults that generate the global water crisis and 4) Ethical categories for water - a solution proposal. Drawing in the end the consideration that water is a fundamental right of the first generation, because it is linked directly to the right to life; the misuse of water directly impacts the environmental, social, economic and technological dimensions of sustainability; there is a need for effective, non-coercive, democratic and non-corrupt governance; there must be participation and information with democratic institutions and water should be considered as water-life, water-citizenship and water economy. Regarding the methodology, the inductive method was used in the research phase; the Cartesian in the data processing phase; and also the inductive in the research report. The techniques of the referent, category, operational concepts, bibliographic research and file were also triggered.
\end{abstract}

INTRODUÇÃO

Key-words: Water; global crisis; right to life; sustainability.

Não restam dúvidas que a água doce é essencial para humanidade, eis que indispensável para manutenção da vida no planeta. É um recurso renovável, mas relativamente escasso em algumas regiões do planeta. Em nível global mesmo tendo-a em abundância existe um mau uso caracterizado tanto pelo uso excessivo, quanto pelo uso inadequado, ou inescrupuloso, o que leva à degradação desse recurso. Assim a pesquisa aqui desenvolvida traz à tona essa discussão tão importante, atual e essencial para sobrevida na terra.

O presente artigo tem como objeto e como objetivo geral a análise de quais os problemas encontrados que agravam a crise global da água. E os objetivos específicos são VERIFICAR a essencialidade da qualidade da água doce; ANALISAR 
quem tem o direito do acesso à água; IDENTIFICAR as falhas que geram a crise global da água, e por fim, DISCUTIR as categorias éticas da água.

Portanto tem como problema central: quais os problemas que agravam a crise global da água e quais as sugestões para garantia desse direito?

Para tanto o presente artigo vem dividido em quatro partes. A primeira aborda a essencialidade da qualidade da água doce. A segunda analisa o acesso à água. $\mathrm{A}$ terceira analisa as falhas que geram a crise global da água e a quarta e última analisa as categorias éticas para água - uma proposta de solução.

Nesse contexto que se revela a relevância social e científica desta pesquisa como modo de se analisar quais os valores e direitos devem ser garantidos para a manutenção desse recurso natural a todos os seres vivos do planeta.

Em linhas gerais é nesse universo que é desenvolvida a pesquisa, restando assim caracterizada sua relevância social, bem como contribuição à Ciência Jurídica.

A metodologia utilizada na fase de Investigação foi o método indutivo; na fase de Tratamento dos Dados foi utilizado o método Cartesiano e, no relatório da pesquisa, foi empregada a base lógica indutiva.

Serão acionadas as técnicas do referente (PASOLD, 2007), da categoria ${ }^{1}$, dos conceitos operacionais ${ }^{2}$, da pesquisa bibliográfica ${ }^{3}$ e do fichamento ${ }^{4}$. (PASOLD, 2007).

\section{A ESSENCIALIDADE DA QUALIDADE DA ÁGUA DOCE}

A água é um dos elementos mais essenciais para manutenção da vida de todos os seres vivos no planeta sendo ela um elemento natural, reciclável e a mais abundante substância simples da biosfera, existindo de forma líquida (doce ou salgada), sólida (doce) e vapor (doce). É um termo feminino de etimologia latina - acqua, é conceituada como substância (H20) líquida e incolor, insípida e inodora, essencial para a vida da maior parte dos organismos vivos, além de excelente solvente para muitas outras substâncias. (D'ISEP, 2010, p. 28).

\footnotetext{
1 "palavra ou expressão estratégica à elaboração e/ou expressão de uma idéia". (PASOLD,2007, p.229).

2 "definição estabelecida ou proposta para uma palavra ou expressão, com o propósito de que tal definição seja aceita para os efeitos das idéias expostas" (PASOLD,2007, p.229)

3 "Técnica de investigação em livros, repertórios jurisprudenciais e coletâneas legais". (PASOLD,2007, p.229).

4 "Técnica que tem como principal utilidade otimizar a leitura na Pesquisa Científica, mediante a reunião de elementos selecionados pelo Pesquisador que registra e/ou resume e/ou reflete e/ou analisa de maneira sucinta, uma Obra, um Ensaio, uma Tese ou Dissertação, um Artigo ou uma aula, segundo Referente previamente estabelecido". (PASOLD,2007, p.229).
} 
Existe um vocabulário técnico hídrico para identificação dos tipos de água existentes, o qual se passa a exemplificar:

a) Quanto ao uso predominante (sistemas de classes de qualidade): (i) águas doces: águas com salinidade igual ou inferior a $0,5 \%$; (ii) águas salobras: águas com salinidade igual ou inferior a 0,5\% e 30\%; (iii) águas salinas: águas com salinidade igual ou superior a $30 \%$.

b) Quanto à localização: (i) águas subterrâneas: as águas que correm naturalmente ou artificialmente no subsolo; (ii) águas superficiais: água que se escoa ou se acumula na superfície do solo.

c) Quanto à potabilidade: 'água potável é a água para consumo humano, cujos parâmetros microbiológicos, físicos, químicos e radioativos atendam ao padrão de potabilidade e que não oferece riscos à saúde. (D'ISEP, 2010, p. 28).

Classificam-se ainda as águas em internas ou interiores (os rios, lagos, mares interiores, o mar territorial, os portos, canais ${ }^{5}$ e ancoradouros ${ }^{6}$, as baías ${ }^{7}$, golfos e estuários) e externas (as águas contíguas e o alto-mar). "Perto de $97 \%$ das águas são salgadas e constituem os oceanos e mares; $2,5 \%$ localizam-se, como sólido (gelo), nas calotas polares e nas geleiras; o resto $(0,72 \%)$ estão nos rios, lagos, etc; e uma ínfima quantidade na atmosfera". (SILVA, 2007, p. 119).

Da água doce existente no mundo são utilizados $73 \%$ na agricultura, $21 \%$ na indústria e $6 \%$ como água potável. A água utilizada na agricultura é grandemente desperdiçada, pois quase $60 \%$ de seu volume total se perde antes de atingir a planta. A água dita potável é de qualidade muito precária, pois nos países pobres chamados de terceiro mundo, mais de $80 \%$ das doenças e mais de um terço da taxa de mortalidade são em decorrência da má qualidade da água utilizada pela população para 0 atendimento de suas diversas necessidades. (ANTUNES, 2006, p. 687).

Com o aumento da população mundial, o desmatamento e o mau uso dos recursos naturais, iniciou-se uma nova era, na qual a água, antes considerada um recurso ilimitado, é entendida como um bem escasso. Essa realidade já é bem evidente no mundo todo, ante a escassez cada vez maior da água.

O Brasil ocupa uma posição de destaque em relação à água, correspondente a $12 \%$ da disponibilidade mundial, ou seja, $180 \mathrm{mil} \mathrm{m3/s}$, em relação a 1,5 milhões de $\mathrm{m} 3 / \mathrm{s}$. Se forem consideradas as razões provenientes de território estrangeiro - Bacia Amazônica, Uruguai e Paraguai -, a vazão brasileira alcança o índice de

\footnotetext{
${ }^{5}$ Parte navegável de via marítima ou a passagem estreita, cavada por processo natural ou artificial, separando dois trechos de costa, ilhas, rochedos, etc., com largura ainda suficiente para permitir a navegação. (LEAL, 1992, p.83)

${ }^{6}$ Lugar destinado ao estacionamento do navio no porto marítimo, fluvial ou lacustre, desde que a embarcação possa ancorar com segurança. $\mathrm{O}$ ancoradouro deve ser protegido do vento e do movimento das águas, pelo aspecto apropriado de um ponto da costa, ou pelas edificações contruídas especialmente para permitir a ancoragem. Diz-se também, fundeadouro. (LEAL, 1992, p.83)

7 Acidente geográfico ou qualquer lugar côncavo do litoral onde se possa aportar. É de grande significação na organização e instalação de um porto. (LEAL, 1992, p.83)
} 
$18 \%$ da disponibilidade hídrica mundial. Todavia, a distribuição da rede hidrográfica do Brasil não corresponde à distribuição espacial da sua população. (GRANZIERA, 2009, p. 185).

Embora o Brasil seja um país com essa importante rede hidrográfica ainda existem muitas disparidades, ou seja, algumas regiões com excesso de uso e outras com parcos acessos. "Daí surge a importância da gestão de recursos hídricos, tanto no âmbito do planejamento como no controle de seu uso, com vistas não apenas a garantir o acesso à água a toda população, como para organizar os diversos tipos de usos desse recurso por seus usuários". (GRANZIERA, 2009, p. 185).

Estima-se que 1200 milhões pessoas não tem acesso a água potável e estima-se que em 2050 teremos 4.000 milhões de pessoas nessa situação.

Os graves problemas que afetam as águas em todo o mundo levaram a comunidade internacional a firmarem princípios para a utilização sustentada das águas e para a sua conservação para as futuras gerações. (LEAL, 1992, p.83).

Os princípios ora referidos foram estabelecidos pela Conferência Internacional sobre Água e Desenvolvimento, realizada em Dublim, Irlanda, no ano de 1992. Os princípios são os seguintes:
a) A água é um recurso finito e vulnerável, essencial para a manutenção da vida, do desenvolvimento e do meio ambiente;
b) O desenvolvimento e a administração da água devem estar baseados em uma abordagem participativa, envolvendo os usuários, planejadores $\mathrm{e}$ elaboradores de políticas públicas em todos os níveis;
c) A mulher desempenha um papel central na administração, na proteção e na provisão da água;
d) A água tem valor econômico e todos os seus usos e deve ser reconhecida como um bem econômico. (ANTUNES, 2006, p. 689/690).

Ocorreu em Brasília, nos dias 18 a 23 de março de 2018 o 8 Fórum Mundial da água, organizado pelo conselho Mundial da água. Esse fórum ocorre a cada três anos e já ocorreu em: Daegu-Coréia do Sul (2015); Marselha - França (2012); Istambul Turquia (2009); Cidade do México- México (2006); Kyoto- Japão (2003); Haia - Holanda (2000) e Marakesh - Marrocos (1997). ${ }^{8}$ A grande discussão gerada esse ano foi se a água deve ser tratada como bem ou como mercadoria, tema que merece discussão separada.

A Constituição da República Federativa do Brasil de 1988 reparte o domínio da água entre a União e os Estados. São da União os lagos, rios e qualquer corrente de

${ }^{8}$ BRASIL. Fórum Mundial da água. www.agenciabrasilia.df.gov.br. Consultado em 02 de março de 2018. 
água em terras de seu domínio, ou que banhem mais de um Estado, sirvam de limites com outros países, ou se estendam a território estrangeiro ou dele provenham (artigo 20, inciso III $^{9}$ da CRFB), assim como o mar territorial (artigo 20, inciso IV da CRFB ${ }^{10}$ ), os potenciais de energia hidráulica (artigos 20, inciso VIII'11 e $176^{12}$ todos CRFB) e os depósitos de águas correntes de obras da União (artigo 26, inciso I do $\mathrm{CRFB}^{13}$ ), como são os açudes construídos nas regiões assoladas pela seca. (SILVA, 2007, p. 121)

São dos Estados as águas superficiais ou subterrâneas, fluentes, emergentes e em depósito, essas águas desde que tenham nascente e foz no seu território, salvo os que estiverem nas condições referidas no artigo 20, inciso III da CRFB, como de domínio da União.

No campo internacional quatro são os textos sobre a proteção das águas continentais que são destacados:

1) La Carta del Agua del Consejo de Europa (1968)

2) El Plan de acción de la Coferencia de las Naciones Unidas sobre el Agua, celebrada en Mar del Plata (Argentina) (1977)

3) El Convenio de Helsinki de 17 de marzo de 1992 sobre protección y sus de los cursos de aguas transfronteirizos y sus lagos internacionales

4) El Convenio de Ramsar de 1971 sobre proteccion de humedales. Los dos últimos tienen un objeto más preciso que los primeros, de carácter más global, y que pueden claficarse de soft law, aunque de ellos cabe deducir ya algunos principios fundamentales sobre la ordenación jurídica del agua, que se reflejará en la legislación nacionales. Son éstos:

El caráter de bien común del agua y el consiguiento deber de todos de usarla adecadamente y no despediciarla.

La consideración de las cuencas hidrográficas como unidad básica de gestión de las aguas superficiales y subterráneas.

La plaificación como instrumento indispensable para una política de administración racional de los recursos a corto y largo plazo.

- La participación de los usuarios en la planificación y administración de los recursos hídricos.

- La elaboración de leyes generales de aguas que den a éstas un tratamiento jurídico unitario". (ALENZA GARCIA, 2001, p. 270).

\footnotetext{
${ }^{9}$ Art. 20. São bens da União (Emenda Constitucional $n^{\circ} 46 / 2005$ )

III - Os lagos, rios e quaisquer correntes de água em terrenos de seu domínio, ou que banhem mais de um Estado, sirvam de limites com outros países, ou se estendam a território estrangeiro ou dele provenham, bem como os terrenos marginais e as praias fluviais.

${ }^{10}$ Art. 20. (...) IV - a ilhas fluviais e lacustres nas zonas limítrofes com outros países; as praias marítimas; as ilhas oceânicas e as costeiras, excluídas, destas, as que contenham a sede dos Municípios, exceto aquelas áreas afetadas ao serviço público e a unidade ambiental federal, e as referidas no artigo 26 , II.

Art. 26. Incluem-se entre os bens dos Estados:

II - as áreas, nas ilhas oceânicas e costeiras, que estiverem no seu domínio, excluídas aquelas sob domínio da União, Municípios ou terceiros.

${ }^{11}$ Art. 20. VIII - os potenciais de energia hidráulica.

${ }^{12}$ Art. 176. As jazidas, em lavra ou não, e demais recursos minerais e os potenciais de energia hidráulica constituem propriedade distinta da do solo, para efeito de exploração ou aproveitamento, e pertencem à União, garantida ao concessionário a propriedade do produto da lavra. (Emenda Constitucional n 6/1995).

${ }^{13}$ Art. 26. Incluem-se entre os bens dos Estados:

I - as águas superficiais ou subterrâneas, fluentes, emergentes e em depósito, ressalvadas, neste caso, na forma da lei, as decorrentes de obras da União.
} 
Essas discussões internacionais sobre a água são indispensáveis para que possamos 'lutar' por sua proteção e pelo seu bom uso com a finalidade de proporcionar seu alcance para todos os seres vivos do planeta.

Segundo Clarissa Ferreira Macedo D'Isep (2010, p. 81):

A crise da água foi denunciada em inúmeras reuniões, conferências, congressos e fóruns, resultando igualmente em várias cartas, declarações, resoluções e projetos e, por conseguinte, na criação de grupos de estudos, parcerias, agências e associações, fazendo dos anos 70 , em especial os 80 , a 'década internacional da água potável e saneamento', logo a década da água; nos anos 90, foi criado o 'Dia Mundial da água' - o dia 22 de março; no ano de 2002, na Conferência de Joanesburgo, a água foi considerada 'chave para 0 desenvolvimento sustentável'; o ano de 2003 foi o 'Ano Internacional da Água'; no ano de 2004, a água se torna o tema da Campanha da Fraternidade da CNBB: 'Água, fonte de vida'. Assim, a água se consagra como um tema mundial.

Como visto acima, a discussão sobre a água há muito tempo já é tema de debates internacionais eis que a crise da escassez da água que existe é presente e não pode ser desconsiderada. Essa realidade é uma crise de insustentabilidade que agrava os problemas de fome no mundo, ao arruinar a pesca e as formas tradicionais de produção agropecuária vinculadas aos ciclos de inundação.

\section{DIREITO AO ACESSO A ÁGUA}

Diante do quadro apresentado acima, um dos maiores desafios para as próximas décadas é, sem sombra de dúvidas, a crise global da água. Os recursos hídricos os quais já são escassos têm sua disponibilidade reduzida em razão da poluição ambiental, do efeito estufa, da destruição da cobertura vegetal, do aumento da população mundial, do desperdício, da inação do ser humano, das leis e dos planos de gestão. (SANTIN, 2013, p. 22).

Este recurso ambiental é tão importante que o Programa das Nações Unidas do Meio Ambiente - PNUMA ao apresentar os objetivos do desenvolvimento sustentável ${ }^{14}$ apresentou como objetivo 06: assegurar a disponibilidade e gestão

\footnotetext{
14 Trata-se de 17 objetivos, todos ligados ao desenvolvimento sustentável e 169 metas para serem acalcados a nível mundial até 2030. Objetivo 01. Acabar com a pobreza em todas as suas formas, em todos os lugares; Objetivo 02. Acabar com a fome, alcançar a segurança alimentar e melhoria da nutrição e promover a agricultura sustentável; Objetivo 3. Assegurar uma vida saudável e promover o bem-estar para todos, em todas as idades; Objetivo 4. Assegurar a educação inclusiva e equidade e de qualidade, e promover oportunidades de aprendizagem, ao longo da vida para todos; Objetivo 5. Alcançar a igualdade de gênero e empoderar todas as mulheres e meninas; Objetivo 6. Assegurar a disponibilidade e gestão sustentável da água e saneamento para todos;Objetivo 7. Assegurar o acesso confiável, sustentável, moderno e a preço acessível à energia para todos; Objetivo 8. Promover o crescimento econômico sustentado, inclusivo e sustentável, emprego pleno e produtivo e trabalho decente para todos;Objetivo 9. Construir infraestruturas resilientes, promover a industrialização inclusiva e sustentável e
} 
sustentável da água e saneamento para todos e todas.

Acerca do caráter fundamental que o Direito ao Acesso à Água possui, assevera Daniel Henrique de Souza Lyra (2016, p. 14):

Alguns direitos fundamentais positivados estão diretamente ligados ao direito de acesso à água. Em sendo um fundamental direito, está umbilicalmente ligado ao direito à vida, à saúde, ao meio ambiente equilibrado e à moradia, além de ter uma íntima relação com a dignidade da pessoa humana, fundamento maior de nossa Constituição.

A autora Bonissoni (2015, p. 71) vai mais além, pois, entende que o direito ao acesso à água está intimamente ligado ao direito à vida, ultrapassando a categoria de direito fundamental de terceira geração podendo também ser classificado como de primeira geração.

E ainda:

O bem fundamental água é classificado por Luigi Ferrajoli como bem social, tendo em vista este ser objeto de direitos fundamentais sociais, relacionados à subsistência, à saúde e a serviços públicos essenciais de abastecimento. (2015, p. 81)

A água, portanto, apesar das discussões sobre o tema, é reconhecida como um direito humano, uma vez que é componente essencial à vida e ao meio ambiente.

Assim, em que pese à importância da água para a vida e, muitas vezes, a dificuldade de se distinguir o que são direito fundamentais de direitos humanos, o acesso a esse bem vem sendo considerado um direito humano fundamental (ou seja, reúnem-se os dois conceitos em uma única nomenclatura) no direito brasileiro. (SANTIN, 2013, p. 33).

Adentrando-se na Legislação brasileira sobre ás águas, destaca-se 0 Decreto n. 24.643/1934, o Código de Águas, a titularidade da propriedade das águas era dividida em:

a) águas públicas (dominiais ou de uso comum do povo, listados no art. $2^{\circ}$ );

fomentar a inovação; Objetivo 10. Reduzir a desigualdade dentro dos países e entre eles; Objetivo 11. Tornar as cidades e os assentamentos humanos inclusivos, seguros, resilientes e sustentáveis; Objetivo 12. Assegurar padrões de produção e de consumo sustentáveis; Objetivo 13. Tomar medidas urgentes para combater a mudança do clima e seus impactos; Objetivo 14. Conservação e uso sustentável dos oceanos, dos mares e dos recursos marinhos para o desenvolvimento sustentável; Objetivo 15. Proteger, recuperar e promover o uso sustentável dos ecossistemas terrestres, gerir de forma sustentável as florestas, combater a desertificação, deter e reverter a degradação da terra e deter a perda de biodiversidade;Objetivo 16. Promover sociedades pacíficas e inclusivas para o desenvolvimento sustentável, proporcionar o acesso à justiça para todos e construir instituições eficazes, responsáveis e inclusivas em todos os níveis;Objetivo 17. Fortalecer os meios de implementação e revitalizar a parceria global para o desenvolvimento sustentável. (https://nacoesunidas.org/pos2015/agenda2030/. Consultado em 27 de fevereiro de 2017). 
b) águas comuns as (de domínio público, bens sem dono, de correntes não navegáveis, conforme 0 art. $7^{\circ}$ );

c) águas particulares (nascentes e todas as águas situadas em terrenos particulares, quando não se enquadrem como públicas ou comuns, nos termos do art. $\left.8^{\circ}\right)$;

Contudo, conforme Frederico Amado (2011, p. 212), com a promulgação da Constituição Federativa do Brasil de 1988, houve uma publicização das águas, conforme se infere:

\begin{abstract}
Destarte, muitos dispositivos do Código de Águas não foram recepcionados pela Constituição Federal de 1988. Demais disso, a Lei 9.433/1997, que instituiu a Política Nacional de Recursos Hídricos, pontifica que a água é bem de domínio público, expressão que deve ser interpretada em sentido estrito, conforme a Constituição, como bem público de uso comum do povo, da União, Estados ou Distrito Federal, a depender.

Esse processo de publicização das águas decorrente de sua escassez, especificamente das águas doces, em virtude do desperdício natural e da poluição irracional das correntes de águas, sendo estratégico para o Estado brasileiro converter as águas em bens públicos, visando uma tutela mais rígida para preservar os interesses nacionais(...).
\end{abstract}

Conforme previsto na Carta Magna de 1988 no seu art. 21, o Sistema Nacional de Recursos Hídricos deveria ser criado e sendo assim foi promulgada a Lei 9.433, de 8 de janeiro de 1997, a qual instituiu a Política Nacional de Recursos Hídricos, que regulamentou o inciso XIX do art. 21 da Constituição Federal, criando o Sistema Nacional de Gerenciamento de Recursos Hídricos.

Essa legislação determina que o Conselho Nacional de Recursos Hídricos deve promover a articulação dos planejamentos nacional, regionais, estaduais e dos setores usuários elaborados pelas entidades que integram o Sistema Nacional de Gerenciamento de Recursos Hídricos. Assim, "Essa lei fundamenta-se no fato de ser a água um bem de domínio público, ser um recurso natural limitado, dotado de valor econômico, que, em situação de escassez, seu uso deve ser prioritariamente o consumo humano e matar a sede de animais". (SILVA, 2007, p.131).

Ser a água considerada de domínio público traz algumas consequências, quais sejam:

1. Necessidade de autorização do Poder Público para as derivações, lançamentos de efluentes para diluição e qualquer atividade que implique a alteração do regime hídrico, consubstanciada na outorga do direito de uso de recursos hídricos, observadas as condições estabelecidas na legislação ambiental e nos processos de licenciamento ambiental; 
2. Sujeição dos usuários á fiscalização e à aplicação de penalidades, quando infringirem as normas relativas ao uso à proteção da água. (GRANZIERA, 2009, p. 191/192).

Portanto, a água constitui um recurso ambiental, sujeitando-se à proteção estabelecida no artigo 225 da Constituição da República Federativa do Brasil, que impõe ao Poder Público e à coletividade o dever de defender o meio ambiente e preservá-lo para as presentes e futuras gerações.

A Lei 9433/97 atendendo ao disposto na Constituição da República Federativa do Brasil, demarca concretamente a sustentabilidade dos recursos hídricos em três aspectos: disponibilidade de água, utilização racional e utilização integrada.

Disponibilidade de água de boa qualidade, isto é, não poluída, para as gerações presentes e futuras. A utilização racional e integrada significa dizer que a água deve ser disponibilizada de forma equânime e que facilite o acesso de todos a este bem, ainda que em quantidade diferente. Os institutos jurídicos hão de ser aplicados no sentido de evitar o monopólio das águas, seja por órgãos públicos, seja por particulares. (MACHADO, 2010, p. 469).

Desta forma essa lei traz como objetivos: a) assegurar à atual e às futuras gerações a necessária disponibilidade de água, em padrões de qualidade adequados aos respectivos usos; b) a utilização racional e integrada dos recursos hídricos, incluindo o transporte aquaviário, com vistas ao desenvolvimento sustentável; c) a preservação e a defesa contra os eventos hidrológicos críticos de origem natural ou decorrentes do uso inadequado dos recursos naturais.

Verificado no primeiro item a necessidade da água para manutenção da vida no planeta e o direito a água, nesse próximo item será feita uma análise quando as falhas que geram a atual crise global da água.

\section{FALHAS QUE GERAM A CRISE GLOBAL DA ÁGUA}

Os dados apresentados até o momento já demonstram a grave crise global da água, porém destacam-se quatro pontos centrais: a) sustentabilidade; b) governança e c) Participação/informação. AGUDO (2018. p.01) destaca também as falhas que geram a crise global da água:

- de sostenibilidad: por contaminación y detracciones abusivas em ríos, lagos y acuíferos, construcción de grandes obras hidráulicas y deflorestación masiva; 
- de inequidad y pobreza: que dispara la vulnerabilidad de las comunidades
más pobres frente a la quiebra de los ecosistemas acuáticos;
- de gobernanza: por problemas de corrupción y las comunidades de
privatización de los servicios de agua y saneamento;
- de institucionalidad democrática global: que permita hacer del agua un
espacio de colaboración entre los pueblos y no de confrontación y dominación ${ }^{15}$.

Quanto à sustentabilidade destaca-se a dimensão ambiental que quanto à água pode-se encontrar uma contaminação tanto orgânica quanto biológica; o uso de agrotóxicos e contaminação que são derramados nos rios decorrentes de atividades industriais, agrárias e de mineração. Podem ser apresentados alguns dados graves dessa poluição da água:

Toxidez de numerosos compostos sintéticos, que alteram profundamente as funções vitais dos organismos aquáticos, podendo afetar a multiplicação celular, a reprodução, etc; radioatividade, que causa graves danos, inclusive genéticas nos organismos aquáticos e no homem que os consumir; biodegradabilidade nula ou insuficiente, que se caracteriza por substâncias resistentes à ação dos organismos que as decompõem; como não são eliminadas (ou são eliminadas muito lentamente) do meio receptor pela autodepuração, seu teor pode sofrer rápido aumento; eurotroficação, que é a devida ao enriquecimento excessivo das águas por sais nutritivos, por. Ex, nitratos, fosfatos, oriundos de detergentes, decorrentes de terras agrícolas ou de despejos industriais e urbanos; degradação das qualidades organolíticas das águas, pois os dejetos despejados dão à água gosto e cheiro desagradável, o que vem a repercutir nas qualidades alimentares dos organismos aquáticos, como, por ex. os peixes, que se podem tornar inconsumíveis; temperaturas, uma vez que os dejetos de águas quentes oriundas de esgotos e de câmaras de resfriamento industrial modificam o regime térmico das águas, afetando a fauna e a flora aquática. (CABRAL, 1978, p. 3 e 4) Por igual, a contaminação dos rios e a construção de usinas hidrelétricas que compromete a produção de pescados em países, por exemplo, como a África e a Ásia que se utilizam principalmente dessa fonte de proteína.

Quanto à dimensão social da sustentabilidade ${ }^{16} 0$ abalo dá-se devido à

\footnotetext{
15 - de sustentabilidade: por contaminação y detrações abusivas em ríos, lagos e aquíferos, construçãode grandes obras hidráulicas e desmatamento massivo

- de inequidade e pobreza: que dispara a vulnerabilidade das comunidades mais pobres frente a quebra dos ecossistemas aquáticos;

- de governança: por problemas de corrupção e as comunidades de privatização dos serviços de água e saneamento.;

- de institucionalidade democrática global: que permite fazer da água um espaço de colaboração entre os povos e confrontação e dominação. (tradução feita livremente pelos autores)

16 Sobre a dimensão social da sustentabilidade consultar: GARCIA, Denise Schmitt Siqueira; BENDLIN, Samara. Dimensão social do Princípio da Sustentabilidade frente ao artigo $6^{\circ}$ da Constituição da República Federativa do
} 
insaciabilidade e irresponsável ambição de desenvolvimento, que fez com que ocorresse a degradação dos ecossistemas e dos aqüíferos, produzindo graves problemas de saúde na população, como por exemplo, a diarréia que é decorrente do uso de água contaminada e é a segunda causa de mortalidade infantil. Segundo informe do PNUD de 2006, estima-se que 5000 crianças menores de 05 anos morrem diariamente por essa razão (corresponde a cinco vezes mais dos que morrem pela AIDS).

A dimensão tecnológica da sustentabilidade também vem abalada devido o uso de técnicas obsoletas que aumentam a contaminação e pioram a saúde pública.

Quanto à dimensão econômica destaca-se a degradação da água doce que piora com o desflorestamento e a expansão da agropecuária. O desflorestamento leva a um rápido empobrecimento do solo, seguido de fenômenos erosivos, redução de infiltração nos aqüíferos.

Assim o uso sustentável da água requer: a) disponibilidade de água de boa qualidade; b) utilização racional; c) utilização integrada. Essas duas exigências significa dizer que a água deve ser disponibilizada de forma equânime e que facilite o acesso de todos a esse bem.

Outro ponto a ser destacado é a fragilidade da governança da água. Entendese aqui governança como um meio e processo capaz de produzir resultados eficazes, sem necessariamente se utilizar de coerção.

Essa governança está ligada à necessidade de participação e informação da população, pois o sistema democrático de leis e instituições sociais e o seu progresso depende de regulação, estabelecida por algum mecanismo em instrumentos normativos capazes de assegurar a concórdia, a paz e o progresso.

A falta de democracia nos governos, junto com a lógica de desregulação imposta pela ONU, pelo FMl e pelo Banco Mundial, sob o argumento de promover a livre concorrência, vem aumentando a contaminação e exploração de rios e aqüíferos. Outro grave problema que afeta a qualidade da água é a ausência de regulação internacional no âmbito industrial e da mineração e os problemas com corrupção. Deste modo, propõe-se como forma de participação: 1. Criação de comitês de bacias hidrográficas e participação, 2. Formação e capacitação, 3. Uso múltiplo da água, 4. Ações em escolas, 5. Saneamento, 6. Navegação fluvial e 7. Mutirões.

Brasil de 1988. Revista Eletrônica Direito e Política, v. 6, p. 419-441, 2011 e GARCIA, Denise Schmitt Siqueira. A necessidade do alcance do mínimo existencial ecológico para garantia da dimensão social da sustentabilidade.

Revista Direito à Sustentabilidade - RDS, v. 1, p. 139-155, 2014. 
O uso múltiplo da água seria induzir o uso adequado dos recursos hídricos, estimulando e dando subsídios financeiros a pessoas que fazem a captação de água da chuva ou em obras que minimizem o desperdício, oferecendo cursos preparatórios para tratamento e utilização da água.

O saneamento com a implementação das estações de tratamento de água e esgoto com políticas municipais de saneamento básico, com prestação de contas periódicas, facilitando o acesso de tecnologias para tratamento do esgoto doméstico.

A navegação fluvial com a fiscalização das embarcações para evitar o vazamento de óleo e notificação das embarcações que provocam erosão na beira dos rios.

Por fim, os mutirões com a promoção da despoluição dos córregos urbanos e nascentes, incentivando e apoiando mutirões e grupos de limpeza de rios e praias

Feita a análise de alguns problemas globais sobre a água agora se apresentará uma proposta de solução.

\section{CATEGORIAS ÉTICAS PARA ÁGUA - UMA PROPOSTA DE SOLUÇÃO}

Diante da realidade apresentada de ser a água um bem fundamental comum e social e necessário para a manutenção da vida no planeta o espanhol Pedro Arrojo Agudo (2018) propõe um serviço público eficiente e bem capacitado com condições de garantir a prestação da água como direito e a sustentabilidade econômica como organismo operador. Referido autor traz diferentes classes de consumo: a) Água como direito humano; b) Água como direito do cidadão; c) Água como negócio.

Como direito humano (água-vida) seria a mínima para sobrevivência que de acordo com a ONU seria 30 a 40 litros de água potável por dia para cada pessoa. Essa quantidade seria para as funções básicas de sobrevivência, tanto dos seres humanos, como dos demais seres vivos, deve haver prioridade máxima, de forma que se garanta a sustentabilidade dos ecossistemas e o acesso de todos a cotas básicas de água de qualidade. Essa quantidade seria fornecida gratuitamente pelo serviço público.

El agua- vida, en funciones básicas de supervivencia, tanto de los seres humanos, como de los demás seres vivos, debe tener prioridad máxima, de forma que se garantice la sostenibilidad de los ecosistemas y el acesso de todos a cuotas básicas de aguas de calidad, como un derenho humano. (AGUDO, 2018, p. 11).

Como direito cidadão (água-cidadania), sugere a colocação de um hidrômetro 
em cada casa, sendo que os primeiros 30 a 40 litros gratuitos e os 100 a 120 litros seguintes pagos de acordo com o que a comunidade considera razoável para poder financiar o serviço que está sendo oferecido.

El agua-ciudadanía, en actividades de interés general, como los servicios de abastecimiento de agua potable y saneamiento, debe situarse en un segundo nivel de prioridad, en el ámbito de los derechos ciudadanos, vinculados a los correspondientes deberes ciudadanos. (AGUDO, 2018, p. 12).

Os próximos litros seriam pagos de forma dobrada com a finalidade de financiar o serviço básico daqueles que não podem pagar seria a água como negócio (água-economia). Como negócio a água teria um valor de matéria-prima geradora de riquezas e, consequentemente, ser sobrado de modo a sustentar as duas primeiras classes de prestação de serviço. Nesse caso, para evitar o desperdício deve aplicar-se critérios de responsabilidade e de racionalidade econômica, bem como deve haver a aplicação de princípios de recuperação integral, com os custos financeiros e custos ambientais.

El agua-economía, en funciones productivas, por encima de lo que podrían considerarse niveles de suficiencia para una vida digna, debe reconocerse en un tercer nivel de prioridad, en conexión con el derecho de cada cual a mejorar su nivel de vida. Es la función en la que se usa la mayor parte del agua y en la que se generan los problemas más relevantes de escasez y contaminación. (AGUDO, 2018, p. 12).

O que se observa é que a água é um bem fundamental e elemento físico indispensável para manutenção de todas as vidas do planeta. Desta forma deve ser garantida pelo menos dentro do mínimo existencial. Assim, a proposta apresentada pelo espanhol Pedro Arrojo Agudo preencheria essa necessidade e ao mesmo tempo evitaria o desperdício e o mau uso desse recurso natural. Fica claro que a água não pode ser tratada como mercadoria, eis que essa especificação violaria o direito a vida.

\section{CONSIDERAÇÕES FINAIS}

A água muito embora seja um dos elementos essenciais para manutenção da vida de todos os seres vivos esta vem sendo muito mal preservada e utilizada pela comunidade global, o que está gerando escassez e comprometendo em alguns lugares a sobrevida de muitos desses seres vivos.

Verificou-se que a preocupação com a proteção da água já remonta algum 
tempo, pois já é consagrado que este bem é finito, tanto que várias regiões do mundo vêm se deparando com crises graves de falta de água. Já em 1992 na Conferência Internacional sobre água e desenvolvimento ocrrida em Dublim na Irlanda houve a fixação de princípios ligados a necessidade de cuidado por este recurso que é finito, vulnerável e essencial para manutenção da vida, do desenvolvimento e do meio ambiente.

Vários são os problemas globais que comprometem esse recurso natural como por exemplo, a poluição ambiental, o efeito estufa, a destruição da cobertura vegetal, o aumento da população mundial, o desperdício, a inação do ser humano, das lei e dos planos de gestão.

Constatou-se que o direito ao acesso à água potável é um direito fundamental de primeira geração, visto que intimamente ligado ao direito à vida e à saúde. Desse modo, nada mais óbvio que o correlacionar com o Princípio da Dignidade da Pessoa Humana, já que um leva a fruição do outro. A vida é o bem mais precioso que o homem possui e todos os elementos que a tornam possível são igualmente preciosos e devem ser protegidos.

O mau uso da água, portando, fere diretamente as dimensões da sustentabilidade. A dimensão ambiental devido tanto a contaminação orgânica como a biológica, o uso de agrotóxicos que são derramados nos rios decorrentes de atividades industriais agrárias e de mineração.

$\mathrm{Na}$ dimensão social o abalo dá-se devido a insacialidade e irresponsável ambição pelo desenvolvimento, que gerou a degradação dos ecossistemas e aquíferos, produzindo graves problemas de saúde na população.

A dimensão tecnológica pelo uso de técnicas obsoletas que aumentam a contaminação e pioram a saúde pública e por fim, a dimensão econômica devido a degradação da água que é gerado pelo desflorestamento e a expansão da agropecuária.

Há a necessidade de alteração da atual governança da água para que esta possa ser não coercitiva, democrática e não corrupta, com a participação e informação de instituições democráticas globais.

Por fim, a água deve ser garantida aos seres vivos dentro, pelo menos, do mínimo existencial, e considerando-a dentro dos critérios da água-vida; água-cidadania e água-economia. 


\section{REFERÊNCIAS BIBLIOGRÁFICAS}

AMADO, Frederico Augusto Di Trindade. Direito Ambiental Esquematizado. São Paulo: MÉTODO, 2011.

ANTUNES, Paulo de Bessa. Direito ambiental. Rio de janeiro: Editora Lúmen Júris, 2006.

ALENZA GARCIA, José Francisco. Manual de derecho ambiental. Madrid: centro de Estúdios Políticos y constitucionales, 2001.

AGUDO, Pedro Arrojo. Crisis global del água: valores y derechos en juego. https://www.fnca.eu/guia-nueva-cultura-delagua/images/documents/Patrimonio/Crisis global del agua.pdf. Consultado em $01 \mathrm{de}$ março de 2018.

BRASIL, Decreto n² 24.643, de 10 de julho de 1934. Disponível em http://www.planalto.gov.br/ccivil_03/decreto/d24643.htm

BRASIL, Lei n. 9433, de 8 de Janeiro de 1997. Disponível em:

http://www.planalto.gov.br/ccivil_03/LEIS/L94

33.htm.

BRASIL. Constituição Federal de 1988. Promulgada em 5 de outubro de 1988. Disponível em <http://www.planalto.gov.br/ccivil_03/constituicao/constituição.htm>.

BRASIL. Fórum Mundial da água. www.agenciabrasilia.df.gov.br. Consultado em 02 de março de 2018.

BRASIL. PEC 258/16.

http://www.camara.gov.br/proposicoesWeb/fichadetramitacao?idProposicao=2093044.

Consultado em 27 de fevereiro de 2018.

BONISSONI, Natammy. 0 acesso à água potável como um instrumento para o alcance da sustentabilidade. Florianópolis: Empório do Direito, 2015.

CABRAL, Armando Henrique Dias Cabral. Proteção ambiental e instrumentos jurídicos. Trabalho classificado no Concurso de monografias prêmio de Ecologia na cidade de Curitiba, 1978

D'ISEP, Clarissa Ferreira Macedo. Água juridicamente sustentável. São Paulo: Revista dos Tribunais. 2010.

GARCIA, Denise Schmitt Siqueira. A necessidade do alcance do mínimo existencial ecológico para garantia da dimensão social da sustentabilidade. Revista Direito à Sustentabilidade - RDS, v. 1, p. 139-155, 2014.

GARCIA, Denise Schmitt Siqueira; BENDLIN, Samara. Loss . Dimensão social do Princípio da Sustentabilidade frente ao artigo $6^{\circ}$ da Constituição da República Federativa do Brasil de 1988. Revista Eletrônica Direito e Política, v. 6, p. 419-441, 2011. 
GRANZIERA, Maria Luiza Machado. Direito ambiental. Rio de Janeiro: Editora Atlas, 2009.

LEAL, Abinael Morais. Dicionário de termos náuticos, marítimos e portuários. São Paulo: Aduanerias, 1992.

LYRA, Daniel Henrique de Souza. Direito De Acesso À Água Subterrânea: A Constituição Federal e os Direitos Fundamentais. Disponível em:

http://aguassubterraneas.abas.org/asubterraneas/article/download/28246/18365. Acesso em Fev. 2016.

MACHADO, Paulo Affonso Leme. Direito Ambiental Brasileiro. 18 ed..São Paulo, Malheiros, 2010. p. 482.

ONU. https://nacoesunidas.org/pos2015/agenda2030/. Consultado em 27 de fevereiro de 2017.

PASOLD, Cesar Luis. Prática da Pesquisa Jurídica e metodologia da pesquisa jurídica. Florianópolis: OAB/SC Editora, 2007.

PES, João Hélio Ferreira. Água potável e a teoria dos bens fundamentais de Luigi Ferrajoli. http://www.publicadireito.com.br/artigos/?cod=da6cb383f8f9e58f. Consultado em 05 de março de 2018.

SILVA, José Afonso. Direito ambiental constitucional. São Paulo: Malheiros, 2007.

SANTIN, Janaína Rigo. CORTE, Thaís Dalla. O direito das águas subterrâneas. No Brasil, no MERCOSUL e na União Europeia, Um estudo comparado. Santa Maria: Ed. Da UFSM, 2013. 